\title{
PREDIKSI PENGGUNA BUS TRANS SARBAGITA DENGAN METODE ADAPTIVE NEURO FUZZY INFERENCE SYSTEM
}

\author{
Slamet Samsul Hidayat ${ }^{1}$, I Putu Eka Nila KenCana ${ }^{2}$, \\ KETUT JAYANEGARA ${ }^{3}$ \\ ${ }^{1,2,3}$ Jurusan Matematika FMIPA Universitas Udayana, Bukit Jimbaran-Bali \\ e-mail: ${ }^{1}$ slamet.s.hidayat@gmail.com, ${ }^{2}$ I.Putu.ENK @ gmail.com, \\ ${ }^{3}$ Ketut_jayanegara@yahoo.com
}

\begin{abstract}
Trans Sarbagita is a public transportation services people at Denpasar, Badung, Gianyar and Tabanan. Trans Sarbagita is aimed to resolve a problems caused by accretion volume of vehicles in Bali. This study conducted to forecast the number of Trans Sarbagita passengers in 2013 using ANFIS. The ANFIS system composed by five layers where each layers has a different function and its divide in two phases, i.e. forward and backward phases. The ANFIS uses a hybrid learning algorithm which is a combination of Least Squares Estimator (LSE) on forwards phases and Error Backpropagation (EBP) on the backward phases. The results show, ANFIS with six inputs with M.F of Pi produces smallest error, compared to seven and eight input and M.F gauss and generalizedbell. Forecast of Trans Sarbagita passenger numbers in 2013 have to fluctuated every day and the average of passenger's Trans Sarbagita for a day is 1627 passengers with MSE equal to 10210 and MAPE is $4.01 \%$.
\end{abstract}

Keywords: ANFIS, fuzzy inference system, Error backpropagation algorithm

\section{Pendahuluan}

Permasalahan yang sering terjadi di setiap daerah, khususnya Provinsi Bali adalah masalah transportasi. Hal ini disebabkan oleh perkembangan dan pertumbuhan jumlah penduduk yang semakin meningkat. Sejalan dengan itu, maka kebutuhan akan alat transportasi juga meningkat. Badan Pusat Statistik Provinsi Bali menunjukkan jumlah penduduk pada tahun 2010 sebesar 3.522.375 jiwa dan tahun 2011 meningkat 1,43 persen menjadi 3.572.831. Sementara itu, jumlah kendaraan bermotor pada tahun 2010 sebesar 1.715.675 unit dan tahun 2011 meningkat 36,71 persen menjadi 2.350.183 unit (BPS, [1]). Dengan kondisi ini, jalanan menjadi penuh dan kerap kali menimbulkan kemacetan pada jam-jam sibuk.

Untuk mengatasi permasalahan tersebut, pemerintah Provinsi Bali berupaya mengatasi permasalahan ini dengan berbagai program. Salah satunya adalah dengan mengoperasikan bus Trans SARBAGITA untuk pertama kalinya pada tahun 2011. Selain itu, pemerintah juga berkewajiban menyediakan dan

\footnotetext{
${ }^{1}$ Mahasiswa Jurusan Matematika FMIPA Universitas Udayana

${ }^{2,3}$ Staf Pengajar Jurusan Matematika FMIPA Universitas Udayana
} 
memfasilitasi masyarakat guna memenuhi kebutuhan akan alat transportasi yang nyaman dan aman. Hal ini tercantum pada UU nomor 22 tahun 2009 tentang LLAJ pasal 138 ayat dua yang berbunyi "Pemerintah bertanggung jawab atas penyelenggaraan angkutan umum [5]” . Seiring dengan semakin banyaknya masyarakat yang menggunakan bus Trans SARBAGITA, maka sudah sewajarnya pemerintah terus meningkatkan pelayanannya kepada pengguna bus Trans Sarbagita dan terus berbenah dengan melaksanakan monitoring dan evaluasi terhadap kegiatan operasional alat transportasi ini. Selain itu pemerintah, dalam hal ini Dinas Perhubungan Informastika dan Komunikasi, yakni UPT Bus Trans Sarbagita memiliki teknik dan metode peramalan terhadap para pengguna bus ke depan. Peramalan atau prediksi ini berfungsi untuk menjaga keberlangsungan pelayanan terhadap masyarakat pengguna alat transportasi ini. Hal ini sejalan dengan pengertian prediksi atau peramalan adalah proses untuk memperkirakan berapa kebutuhan di masa datang yang meliputi kebutuhan dalam ukuran kuantitas, kualitas, waktu dan lokasi yang dibutuhkan dalam rangka memenuhi permintaan barang ataupun jasa [6].

Begitu pentingnya peramalan bagi manusia, maka perkembangan teknik atau metode peramalan terus bermunculan dan berkembang dari masa ke masa, salah satunya adalah metode Adaptive Neuro Fuzzy Inference System (ANFIS) berbasis soft computing. ANFIS merupakan metode peramalan yang menggabungkan fungsi yang terdapat pada Fuzzy Logic dan Neural Network. Logika fuzzy memiliki keunggulan dalam memodelkan aspek kualitatif dari pengetahuan manusia dan proses pengambilan keputusan (reasoning) sebagaimana dilakukan oleh manusia dengan menerapkan basis aturan atau basis kaidah [3]. Jaringan syaraf merupakan salah satu representasi buatan dari otak manusia yang selalu mencoba untuk mensimulasikan proses pembelajaran pada

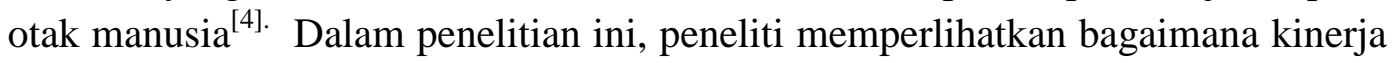
metode ANFIS dalam meramalkan jumlah penumpang bus Trans SARBAGITA serta gambaran hasil peramalan jumlah penumpang pada tahun 2013.

\section{Metode Penelitian}

Data yang digunakan dalam penelitian ini adalah data sekunder yang didapat dari UPT bus Trans SARBAGITA. Data tersebut merupakan data harian jumlah penjualan tiket bus Trans SARBAGITA koridor dua dari hari Minggu tanggal 28 Agustus 2011 sampai hari Sabtu tanggal 29 Desember 2012. Sedangkan metode prediksi atau peramalan yang digunakan dalam penelitian ini adalah ANFIS model TSK orde satu dengan pertimbangan kemudahan komputasi. Proses fuzzyfikasinya menggunakan tiga membership function yaitu Pi, Gaussian, Generalizerdbell. Sedangkan untuk mendapatkan model inputnya, menggunakan model dari lag pertama yang melebihi batas standar error secara visual pada plot PACF. 
Langkah-langkah analisis data dalam penelitian ini sebagai berikut:

1. Mencari model input.

2. Membagi data menjadi 2 kelompok, yaitu data untuk proses pembelajaran program ANFIS dan data untuk validasi.

3. Melakukan peramalan menggunakan ANFIS dengan tahapan sebagai berikut:

a. Melakukan proses inisialisasi, yaitu menentukan jumlah iterasi, step size dan parameter premis.

b. Melakukan pembelajaran arah maju menggunakan metode LSE dan pembelajaran arah mundur menggunakan metode EBP sampai error dan jumlah iterasi sebesar 500.000.

c. Melakukan proses pengecekan.

d. Memilih model terbaik dari setiap fungsi keanggotaan berdasarkan nilai MAPE dan MSE terkecil.

4. Melakukan peramalan jumlah penumpang beberapa periode ke depan pada tahun 2013.

\section{Hasil dan Pembahasan}

Tahap awal analisis metode ANFIS adalah menentukan model input. Pada penelitian ini model input menggunakan model dari lag pertama yang melebihi batas standar error secara visual pada plot PACF. Langkah pertama adalah plot deret waktu untuk mengetahui pola data. Berikut ini diagram plot deret waktu data jumlah penumpang bus Trans SARBAGITA pada hari Minggu tanggal 28 Agustus 2011 sampai hari Sabtu tanggal 29 Desember 2012.

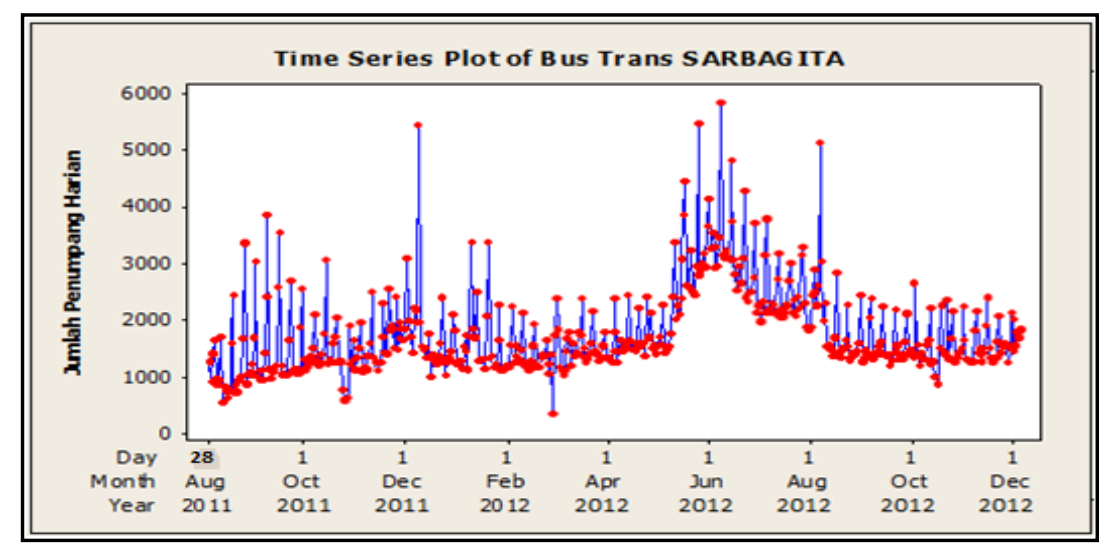

Gambar 1. Plot Deret Waktu Data Jumlah Penumpang.

Pada plot deret waktu dapat dilihat bahwa data masih belum stasioner dalam mean dan varians, untuk lebih jelas dibuat plot Box-Cox dan ACF-nya. 


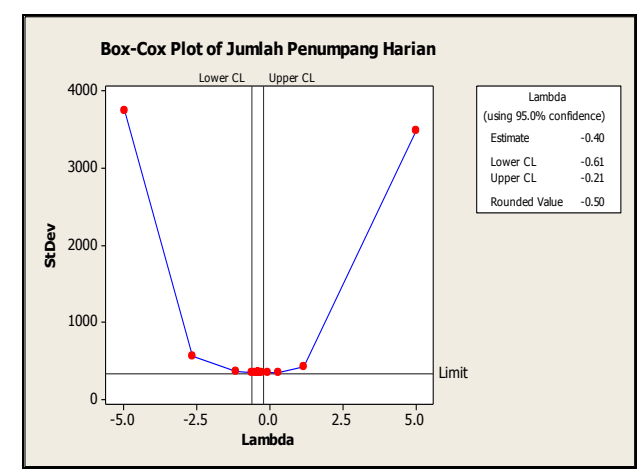

(a)

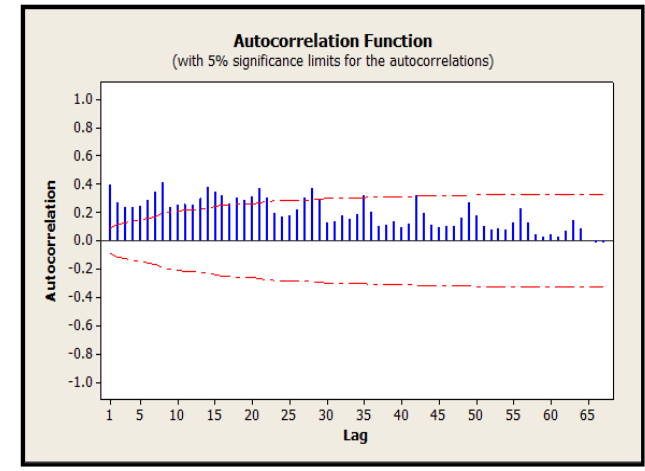

(b)

Gambar 2. (a) Plot Box-Cox, (b) Plot ACF Data Asli.

Pada Gambar 2. (a) plot Box-Cox jumlah penumpang bus Trans SARBAGITA dapat dilihat bahwa data tidak stasioner dalam varian yang ditunjukkan dari nilai estimasinya sebesar -0.40 sehingga perlu ditransformasi sebesar $\frac{1}{\sqrt{Z_{t}}}$ dikarenakan nilai estimasinya mendekati nilai -0.05 [2]. Pada Gambar 2 .(b) plot ACF jumlah penumpang bus Trans SARBAGITA dapat dilihat bahwa meannya masih tidak stasioner maka akan dilakukan diffrencing untuk menstasionerkannya
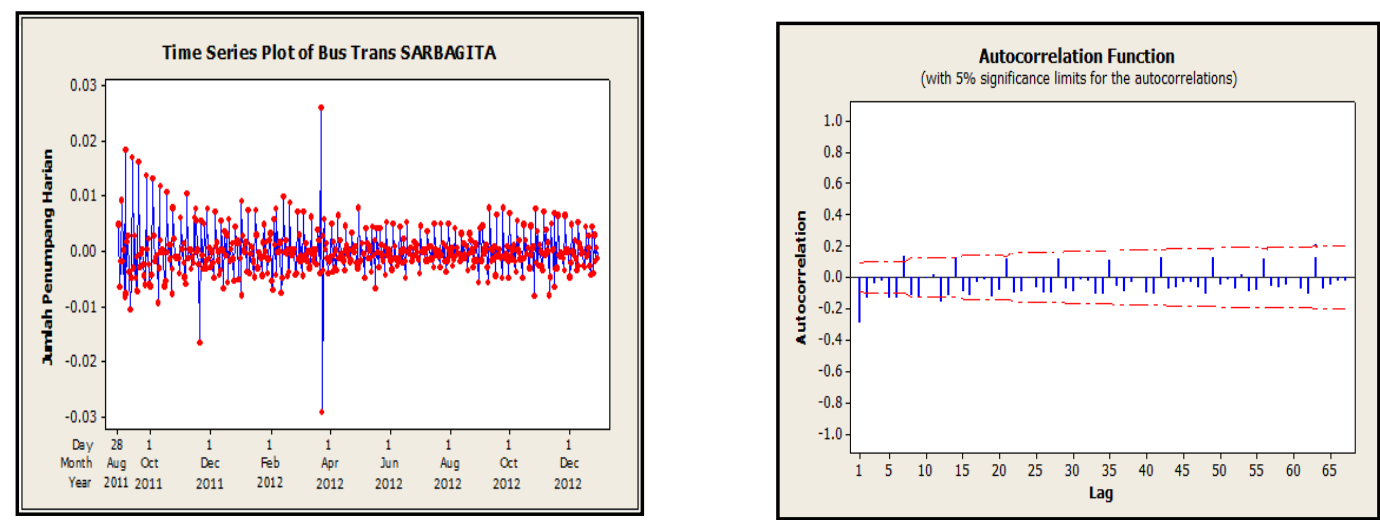

(a) (b)

Gambar 3. (a) Plot Deret Waktu Data , (b) Plot ACF Data yang Sudah Didifferencing.

Selanjutnya perhatikan gambar 3. (a) plot deret waktu data yang sudah didifferencing dan ditranformasi dan gambar 3. (b) plot ACF data yang sudah didifferencing dan ditranformasi menunjukkan bahwa data sudah stasioner dalam mean dan varians, yang ditunjukkan dengan pola data yang menyebar secara seimbang. Tahap selanjutnya adalah membuat plot PACF untuk mendapatkan pola input ANFIS. 


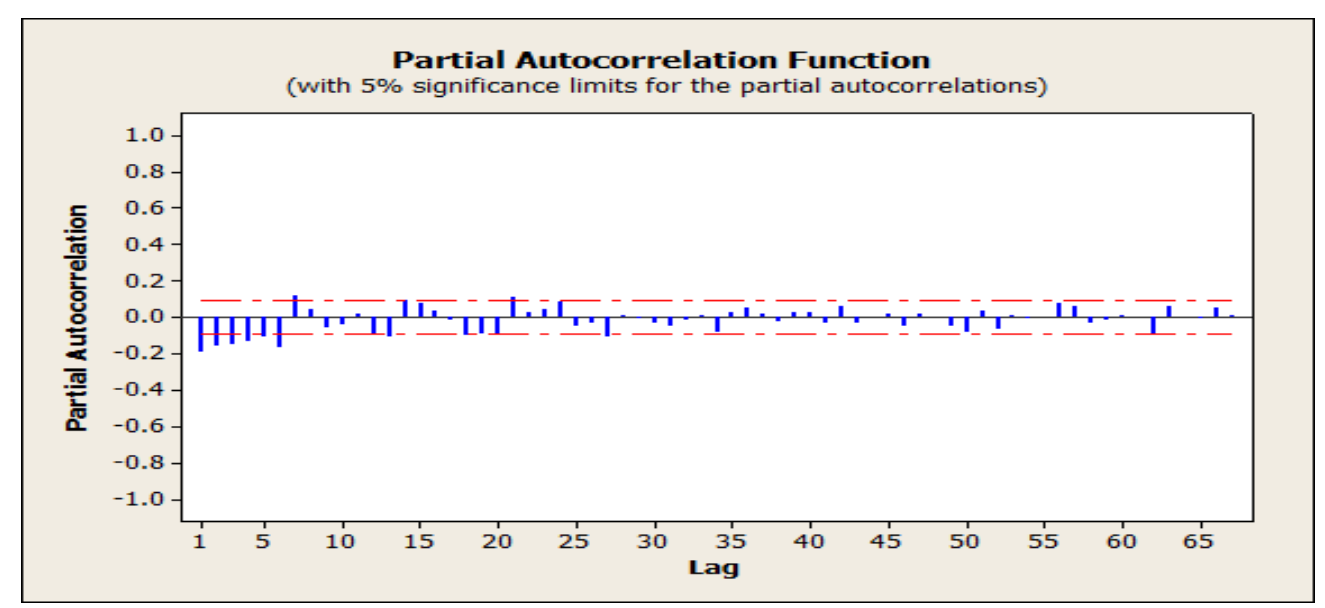

Gambar 4. Plot PACF Data yang Sudah Didifferencing.

Gambar 4. merupakan plot PACF dari data yang sudah didifferencing dan ditranformasi, bisa dilhat bahwa tujuh lag pertama yang melebihi batas standar error akan digunakan sebagai model input ANFIS yaitu lag 1, lag 2, lag 3, lag 4, lag 5, lag 6 dan lag 7. Karena pada model yang didapat terjadi pengulangan data mingguan maka model input yang didapat akan ditambah satu variabel dan dikurangi satu variabel sehingga terdapat tiga model input yang akan dicoba yang ditunjukkan pada Tabel 1.

Tabel 1. Model Input ANFIS

\begin{tabular}{|c|c|c|}
\hline No. & Model Input & Output \\
\hline 1 & $X_{1}, X_{2}, X_{3}, X_{4}, X_{5} X_{6}$ & $X_{7}$ \\
\hline 2 & $X_{1}, X_{2}, X_{3}, X_{4}, X_{5} X_{6}, X_{7}$ & $X_{8}$ \\
\hline 3 & $X_{1}, X_{2}, X_{3}, X_{4}, X_{5} X_{6}, X_{7}, X_{8}$ & $X_{9}$ \\
\hline
\end{tabular}

Sumber: Data Diolah, 2013.

Keterangan:

$X_{1}=$ hari pertama. $\quad X_{2}=$ hari kedua $. \quad X_{3}=$ hari ketiga.

$X_{4}=$ hari keempat. $\quad X_{5}=$ hari kelima $. \quad X_{6}=$ hari keenam.

$X_{7}=$ hari ketujuh $\quad X_{8}=$ hari kedelapan. $X_{9}=$ hari kesembilan

Setalah mendapatkan model input, maka data bus Trans SARBAGITA dibagi menjadi dua kelompok yaitu data untuk proses pembelajaran sebesar 70 persen dari total data yang digunakan yaitu 344 data dan data untuk proses pengecekan sebesar 30 persen dari total data yang digunakan yaitu 147 data.

Tahap berikutnya, data pembelajaran diinput menggunakan model pada Tabel 1. kemudian dilakukannya proses pembelajaran dengan jumlah iterasi maksimum sebesar 500.000 iterasi, step size sebesar 0.01 dan toleransi error sebesar $1 \times 10^{-6}$. Untuk parameter premis awal akan ditentukan berdasarkan fungsi genparam yang ada pada MATLAB. Hasil proses pembelajaran pada masingmasing percobaan diperoleh nilai MSE dan MAPE seperti Tabel 2. 
Tabel 2. Nilai MSE dan MAPE Setiap Kombinasi Model Input.

\begin{tabular}{|c|l|l|r|r|}
\hline $\begin{array}{c}\text { Kombinasi } \\
\text { Model }\end{array}$ & \multicolumn{1}{|c|}{ Model Input } & \multicolumn{1}{|c|}{$\begin{array}{c}\text { Jenis Fungsi } \\
\text { Keanggotaan }\end{array}$} & \multicolumn{1}{c|}{ MSE } & \multicolumn{1}{c|}{ MAPE } \\
\hline 1 & Enam Input $\left(\mathrm{X}_{1}, \mathrm{X}_{2}, \mathrm{X}_{3}, \mathrm{X}_{4}, \mathrm{X}_{5}, \mathrm{X}_{6}\right)$ & Generalizerd bell & 32934 & $5.86 \%$ \\
\hline 2 & Enam Input $\left(\mathrm{X}_{1}, \mathrm{X}_{2}, \mathrm{X}_{3}, \mathrm{X}_{4}, \mathrm{X}_{5}, \mathrm{X}_{6}\right)$ & Gaussian & 131854 & $10.06 \%$ \\
\hline $\mathbf{3}$ & Enam Input $\left(\mathrm{X}_{\mathbf{1}}, \mathrm{X}_{\mathbf{2}}, \mathrm{X}_{\mathbf{3}}, \mathrm{X}_{\mathbf{4}}, \mathrm{X}_{5}, \mathrm{X}_{\mathbf{6}}\right)$ & $\mathbf{P i}$ & $\mathbf{1 4 3 1 4}$ & $\mathbf{3 . 5 5 \%}$ \\
\hline 4 & Tujuh Input $\left(\mathrm{X}_{1}, \mathrm{X}_{2}, \mathrm{X}_{3}, \mathrm{X}_{4}, \mathrm{X}_{5}, \mathrm{X}_{6}, \mathrm{X}_{7}\right)$ & Generalizerd bell & 133066 & $10.12 \%$ \\
\hline 5 & Tujuh Input $\left(\mathrm{X}_{1}, \mathrm{X}_{2}, \mathrm{X}_{3}, \mathrm{X}_{4}, \mathrm{X}_{5}, \mathrm{X}_{6}, \mathrm{X}_{7}\right)$ & Gaussian & 191868 & $11.56 \%$ \\
\hline 6 & Tujuh Input $\left(\mathrm{X}_{1}, \mathrm{X}_{2}, \mathrm{X}_{3}, \mathrm{X}_{4}, \mathrm{X}_{5}, \mathrm{X}_{6}, \mathrm{X}_{7}\right)$ & Pi & 46613 & $7.08 \%$ \\
\hline 7 & Delapan Input $\left(\mathrm{X}_{1}, \mathrm{X}_{2}, \mathrm{X}_{3}, \mathrm{X}_{4}, \mathrm{X}_{5}, \mathrm{X}_{6}, \mathrm{X}_{7}, \mathrm{X}_{8}\right)$ & Generalizerd bell & 134707 & $12.11 \%$ \\
\hline 8 & Delapan Input $\left(\mathrm{X}_{1}, \mathrm{X}_{2}, \mathrm{X}_{3}, \mathrm{X}_{4}, \mathrm{X}_{5}, \mathrm{X}_{6}, \mathrm{X}_{7}, \mathrm{X}_{8}\right)$ & Gaussian & 186857 & $13.57 \%$ \\
\hline 9 & Delapan Input $\left(\mathrm{X}_{1}, \mathrm{X}_{2}, \mathrm{X}_{3}, \mathrm{X}_{4}, \mathrm{X}_{5}, \mathrm{X}_{6}, \mathrm{X}_{7}, \mathrm{X}_{8}\right)$ & Pi & 70859 & $8.55 \%$ \\
\hline
\end{tabular}

Sumber: Data Diolah, 2013

Pada Tabel 2. ditunjukkan bahwa nilai terkecil untuk MSE sebesar 14314 dan nilai MAPE sebesar 3,55 \% didapat dari kombinasi antara model enam input dengan jenis fungsi keanggotaan $P i$.

Proses selanjutnya adalah testing. Pada proses testing, nilai parameter linear dan non linear yang digunakan adalah pada iterasi ke 500.000. Hasil proses testing berupa nilai MSE dan MAPE dapat dilihat pada Tabel 3.

Tabel 3. Nilai MSE dan MAPE Proses Testing.

\begin{tabular}{|c|l|c|c|}
\hline No & Membership Function & MSE & MAPE \\
\hline 1 & Generelized bell & 25649 & 7.345 \\
\hline 2 & Gaussian & 29035 & 9.101 \\
\hline 3 & $P i$ & 10210 & 4.011 \\
\hline
\end{tabular}

Sumber: Data Diolah, 2013.

Tabel 3. menunjukkan metode ANFIS yang menghasilkan nilai ramalan dengan nilai MSE dan MAPE terkecil pada data testing diperoleh pada fungsi keanggotaan $P i$. Nilai MAPE yang dihasilkan adalah sebesar 4,011\% dan MSE yang dihasilkan adalah 10210, sehingga fungsi keanggotaan $P i$ yang digunakan untuk meramalkan jumlah penumpang bus Trans SARBAGITA pada tahun 2013 karena memiliki nilai error terkecil. Diagram hasil prediksi dengan metode ANFIS kombinasi enam input dan fungsi keanggotaan $P i$ dapat dilihat pada Gambar 5.

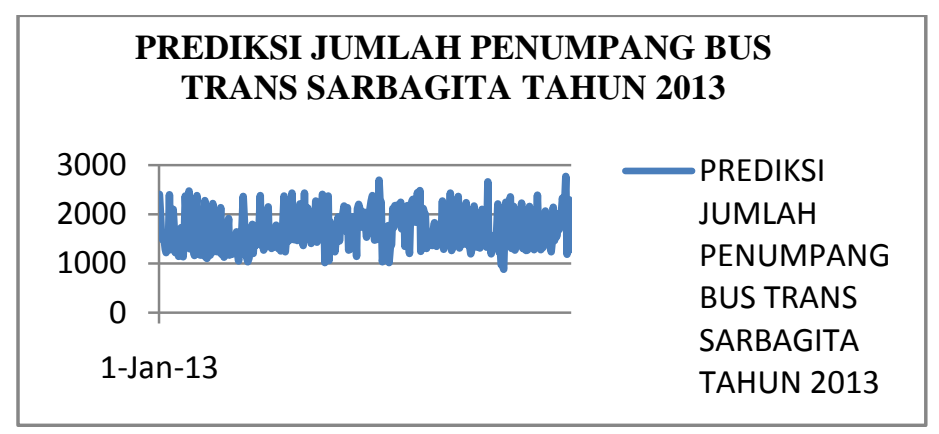

Gambar 5. Grafik Hasil Prediksi Tahun 2013. 
Pada Gambar 5. menunjukkan bahwa hasil prediksi pada tahun 2013 mengalami fluktuasi setiap harinya dan rata-rata jumlah penumpang setiap hari sebesar 1.627 penumpang. Hasil ramalan menunjukkan bahwa jumlah penumpang terbanyak terjadi pada tanggal 26 Desember 2013 yaitu sebanyak 2.776 penumpang dan jumlah penumpang terendah terjadi pada tanggal 1 November 2013 yaitu sebanyak 886 .

\section{Kesimpulan}

Berdasarkan hasil yang telah diperoleh pada kasus peramalan jumlah penumpang bus Trans SARBAGITA tahun 2013, dapat ditarik kesimpulan bahwa peramalan jumlah penumpang bus Trans SARBAGITA menggunakan metode ANFIS dengan kombinasi enam input dan fungsi keanggotaan $P i$ menghasilkan error terkecil yaitu MSE sebesar 10210 dan MAPE sebesar 4,011\%, dan mengalami fluktuasi setiap harinya dengan rata-rata jumlah penumpang sebesar 1627 penumpang.

\section{Daftar Pustaka}

[1] BPS. 2011. Bali Dalam Angka 2011. Bali: BPS Provinsi Bali.

[2] Box, G.E.P, dan G.M. Jenkins. 1976. Time Series Analisis: Forecasting and Control, Revised Edition. San Fransisco: Holden-Day.

[3] Kusumadewi, Sri dan Sri Hartati. 2010. Neuro-Fuzzy (Integrasi Sistem Fuzzy dan Jaringan Syaraf). Edisi-2. Yogyakarta: Graha Ilmu

[4] Kusumadewi, Sri. 2003. Artificial Intelegence (Teknik dan Aplikasi). Yogyakarta: Graha Ilmu

[5] Undang-Undang Republik Indonesia. 2009. Undang-Undang Republik Indonesia Nomor 22 Tahun 2009 tentang Lalu Lintas dan Angkuta Jalan. Jakarta.

[6] Yamit, Zulian. 2005. Manajemen Persediaan. Yogyakarta: Ekonisia. 